\title{
Intrauterine levobupivacaine for pain control during intrauterine device insertion
}

\author{
Nilufer Akgun ${ }^{1 *}$, Esra Keskin'1, Muberra Namlı Kalem¹, Batuhan Bakirarar ${ }^{2}$
}

\author{
${ }^{1}$ Department of Obstetrics and Gynecology, Turgut Ozal University, Ankara, Turkey \\ ${ }^{2}$ Department of Biostatistics, Ankara University, Faculty of Medicine, Ankara, Turkey
}

Received: 12 December 2016

Accepted: 06 January 2017

\author{
*Correspondence: \\ Dr. Nilufer Akgun, \\ E-mail: niluferakgun80@ hotmail.com
}

Copyright: $\odot$ the author(s), publisher and licensee Medip Academy. This is an open-access article distributed under the terms of the Creative Commons Attribution Non-Commercial License, which permits unrestricted non-commercial use, distribution, and reproduction in any medium, provided the original work is properly cited.

\section{ABSTRACT}

Background: Safe, effective, long term and a reversible contraception method is offered by intrauterine devices (IUDs). The objective was to determine the potency of intrauterine administration of $5 \mathrm{cc}$ levobupivacain for pain relief with IUD insertion, when compared with saline placebo.

Methods: This was a prospective randomized, double blind placebo-controlled trial undergoing IUD insertion. The trial medication was intrauterine anesthesia, either $5 \mathrm{~mL} \mathrm{0.9 \%} \mathrm{saline} \mathrm{(control} \mathrm{group),} \mathrm{or} 5 \mathrm{~mL} 0.5 \%$ levobupivacaine. Our primary outcome was self-reported pain scores on a $10 \mathrm{~cm}$ visual analogue scale (VAS) immediately following IUD insertion.

Results: 95 women were enrolled, and data for 88 women were analyzed. In IUD insertion procedure, no difference was observed between groups during teneculum placement and solution administration, in the course of VAS scores $(p=0.349, p=0.396)$. There was a significant difference in the VAS scores measuring pain suffering during and after IUD procedure $(\mathrm{p}=0.001)$.

Conclusions: Intrauterine instillation of $5 \mathrm{cc}$ of levobupivacaine along with saline solution reduces pain with IUD insertion when compared to intrauterine saline placebo. Broad deviation in pain scores and persistent pain after IUD insertion recommends that patient would benefit from more functioning method of pain control than before at IUD insertion and during the post interval.

Keywords: IUD, Levobupivacaine, Pain

\section{INTRODUCTION}

Safe, effective, long term and a reversible contraception method is offered by intrauterine devices (IUDs). ${ }^{1}$ Pain occurs during the insertion because of the tenaculum connected to the cervix to fix the cervical canal and passing the uterine sound in order to treat IUD insertion, that more makes pain worse than before by inducing uterine contraction. ${ }^{2}$

In Turkey, the methods of contraception women most commonly use are withdrawal (64 percent), male condom (46 percent), IUD (39 percent) and the pill (31 percent). ${ }^{3}$
In our country, IUD is preferred by thirty point nine percent of modern contraceptive method users $(39 \%$ of reproductive aged women). ${ }^{3}$

Pain occurring during insertion is the major defect of the method. ${ }^{4}$ Nulliparity, prolonged time since last pregnancy or last menses, history of dysmenorrhea, not breastfeeding at the present time, expected pain and earlier age are the factors affiliated with pain amid IUD insertion. ${ }^{5}$ To ensure the IUD insertion into pain control, various medications are used, both $400 \mathrm{mg}$ and $800 \mathrm{mg}$ of ibuprofen previous insertion are widely used, 
misoprostol, topical $2 \%$ lidocaine gel or sprey on the cervix, paracervical block and intrauterine anesthesia. ${ }^{6-9}$

Intrauterine instillation of a topical anesthetic is easy, relatively painless and promising for adequate analgesia during endometrial procedures moderate evidence to support use in hysteroscopy, and insufficient evidence to recommend for or against use in IUD insertion, IUD removal. ${ }^{10,11}$ Various studies have validated the VAS as an efficient way to assess the intensity of sharp pain and it has been used in past IUD insertion studies before. ${ }^{12,13}$ Besides intrauterine anesthesia effectiveness for pain relief in gynecologic procedures that involve the uterine cavity has been demonstrated in many studies it has been variably reported to be ineffective or effective in reducing pain however, in most of the studies, it has been demonstrated to be effective. ${ }^{15,16,17}$ Levobupivacaine is a long-acting amide local anaesthetic that is effective when administered as an local infiltration. ${ }^{18}$

This study purposed to test the efficacy of pain levels during IUD insertion comparing intrauterine instillation of levobupivacaine with placebo.

\section{METHODS}

This prospective randomized, double-blinded, placebocontrolled trial was performed in the Department of Obstetrics and Gynecology, Faculty of Medicine, Turgut Ozal University, Ankara, Turkey. 88 women between 1845 years of age presented to the hospital in purpose of IUD insertion. The human ethics committee of the university approved the study.

The study group consists of 95 women who were scheduled for IUD application. Any contraindication to IUD placement, women with allergy to levobupivacaine or copper, cervicitis, history of pelvic inflammatory disease throughout the last three months, profuse uterine bleeding, pregnancy, cervical stenosis or vaginismus, or any history of cervical conization and who were not able to see how to score their pain on a visual analogue scale (VAS) were included in exclusion criteria. Desired type of IUD was chosen by subjects, either the CuT380A IUD or the levonorgestrel IUD. We didn't have any nulliparous patients who undergone IUD insertion in this study. Thus the pain scores of nulliparous and multiparous patients couldn't be compared.

Among the 95 patients, 88 were deemed to be eligible and were informed about the research protocol.

Prior to the procedure, patient demographic data age, gravidity, parity, Body mass index (BMI), and history of cesarean section. $5 \mathrm{~mL}$ of $0.9 \%$ saline for the control group, or $5 \mathrm{~mL}$ of $0.5 \%$ levobupivacaine were the trial medications chosen for the experimental groups. Identical, colourless, unlabelled $10 \mathrm{~mL}$ disposable syringes were used to place the solutions into. All resident physicians and nurses caring for study subjects were blinded to the type of solution.

Routine pelvic examination was trailed by speculum brought into the vagina for perception of the cervix. $10 \%$ povidone iodine solution was used to clean the cervix and vagina. The upper limb of the cervix was grasped by tenaculum and it was pulled slightly. Unlabelled test solution $(5 \mathrm{~mL})$ was instilled through the endocervix into the uterine cavity with the help of 18 gauge angiocatheter. IUD insertion followed $5 \mathrm{~mL}$ of intrauterine $0.5 \%$ levobupivacaine or $5 \mathrm{~mL}$ saline (control group) received by each patient. None of the patients was exposed to any oral or parenteral analgesic drugs. The speculum was evacuated after installation; however the angiocatheter was stayed active for 15 min before it was pulled back to reduction and permits the sedative to produce results. After 15 minutes of waiting IUD was applied in the standard method.

Information related the process of the IUD insertion was given to all participants and awaiting them to score their ongoing agony level by using visual pain scale during the steps of the procedure. Zero point (0) was a grade for as no pain and the worst pain was graded as ten point (10) in this scale. During the procedure of IUD insertion, degree of pain was specified by patients by their marking a mark on this scale at 4 points. These steps were performed immediately teneculum application, after the solution instillation and IUD insertion and 15 minutes after the procedure. In cases of unbearable pain, the procedure was ended instantly, and the record of the agony score wasn't made. The patients were observed for $60 \mathrm{~min}$ in a recovery room and assessed for side effects and complications.

SPSS version 11.5 for windows (SPSS, Inc., Chicago) was used to perform Statistical analysis. Either Anova test or Kruskal-Wallis test was used to compare demographical variables, complication rates and pain scores. Spearman's correlation test was used to perform correlation analysis. Frequencies of categorical variables were compared with the Chi-square tests (x2). Significance level of $\mathrm{p}$ value was set as $<0.05$.

\section{RESULTS}

Enrolled in the study were 95 women and allocated into two groups randomly. Seven patients were excluded from the study: three due to pain during speculum insertion and four due to cervical stenosis. In terms of tested demographic variables all groups were similar (Table 1).

When looking at the delivery stories of the patients in the levobupivacaine group, 20 patients $(57 \%)$ had carried out vaginal delivery, 14 patients $(40 \%)$ had given birth with $\mathrm{C} / \mathrm{S}$ and 1 patient $(3 \%)$ had both carried out vaginal delivery and given birth with $\mathrm{C} / \mathrm{S}$. It was seen in the control group that 32 patients $(58 \%)$ had carried out vaginal delivery, $20(37 \%)$ patients had given birth with 
C/S and 2 patients (4\%) had both carried out vaginal delivery and given birth with $\mathrm{C} / \mathrm{S}$. No statistically significant difference was observed by types of delivery between the two groups $(\mathrm{p}=0.359)$.

Table 1: Demographic and clinical traits of groups.

\begin{tabular}{|c|c|c|c|c|c|}
\hline & \multicolumn{5}{|l|}{ Group } \\
\hline & \multicolumn{2}{|c|}{ Levobupivacain $(n=35)$} & \multicolumn{3}{|c|}{ Control $(n=53)$} \\
\hline & Mean \pm SD & Median (min.--max.) & Mean \pm SD & Median (min.-max.) & p value \\
\hline Age & $35.60 \pm 6.99$ & $35.00(22.00-48.00)$ & $32.30 \pm 6.97$ & $32.00(20.00-46.00)$ & 0.033 \\
\hline BMI & $26.35 \pm 3.66$ & $26.13(19.49-37.39)$ & $26.25 \pm 3.94$ & $26.45(18.65-41.02)$ & 0.904 \\
\hline Gravida & $2.29 \pm 1.36$ & $2.00(1.00-7.00)$ & $2.48 \pm 1.15$ & $2.00(1.00-6.00)$ & 0.247 \\
\hline Parity & $2.09 \pm 1.07$ & $2.00(1.00-5.00)$ & $2.23 \pm 1.04$ & $2.00(1.00-5.00)$ & 0.460 \\
\hline $\mathbf{C} / \mathbf{S}$ & $1.07 \pm 0.27$ & $1.00(1.00-2.00)$ & $1.00 \pm 0.00$ & $1.00(1.00-1.00)$ & 0.210 \\
\hline
\end{tabular}

In two groups, the types of the complications were all similar. In total, 3 patients had vasovagal syncope, 2 patients in the levobupivacaine group, one in saline group. Also, vasovagal symptoms like nausea and vomiting were encountered in the similar groups $(\mathrm{p}=0.20)$. None of the patients in the study had a bleeding or uterine perforation. Dilatation for IUD insertion were required none patients in each group.

Table 2: Distribution of pain scores about groups. VAS Visual analogue scale.

\begin{tabular}{|c|c|c|c|c|c|}
\hline & \multicolumn{5}{|l|}{ Group } \\
\hline & \multicolumn{2}{|c|}{ Levobupivacaine } & \multicolumn{2}{|l|}{ Control } & \multirow[t]{2}{*}{ p value } \\
\hline & Mean \pm SD & Median (min.-max.) & Mean \pm SD & Median (min.-max.) & \\
\hline Teneculum application & $0.74 \pm 0.77$ & $0.00(0.00-2.00)$ & $0.57 \pm 0.71$ & $1.00(0.00-2.00)$ & 0.105 \\
\hline Solution instilled & $1.73 \pm 1.03$ & $2.00(0.00-4.00)$ & $1.55 \pm 1.44$ & $1.00(0.00-5.00)$ & 0.241 \\
\hline IUD application & $3.37 \pm 1.09$ & $3.00(1.00-6.00)$ & $5.52 \pm 2.65$ & $5.00(1.00-10.00)$ & $<0.001 *$ \\
\hline After the procedure & $1.57 \pm 0.80$ & $2.00(0.00-3.00)$ & $2.76 \pm 1.42$ & $3.00(0.00-6.00)$ & $<0.001 *$ \\
\hline
\end{tabular}

*Significant difference between levobupivacaine and control groups $(\mathrm{p}<0,05)$.

While pain scores of the groups were correlated, scores in the intrauterine levobupivacaine group during the IUD application and after the procedure, were observed notably lower than the control group $(\mathrm{p}<0.001$ and $\mathrm{p}<0.001$ respectively).

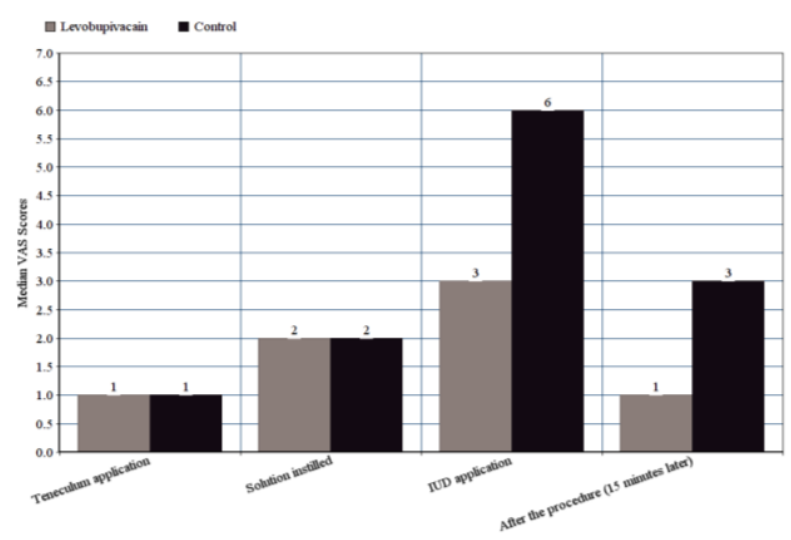

Figure 1. Distribution of VAS scores during tenaculum application, solution instillation, IUD application and after the procedure between levobupivacaine and control groups.
Pain scores distribution and median pain scores according to groups are shown in Table 2.

Figure 1 shows the comparison of pain scores between levobupivacaine and control groups during the applications.

\section{DISCUSSION}

In the present study, we found that women who accepted intrauterine $5 \mathrm{~mL}$ of levobupivacaine have reduced pain IUD insertion compared to placebo saline infusion. In present study, while no difference was observed between groups during tenaculum placement and solution instillation, in the course of VAS scores; there was a significant difference about pain suffering during and after IUD procedure.

Intrauterine device application is a mild to moderate painfull gynecological outpatient procedure. Procedural pain appears to arise by tenaculum placement, and servical dilatation and uterine contraction and after the procedure. In IUD insertion, the methods used for pain management are mainly NSAIDs as well as oral analgesic 
drugs, use of misoprostol for cervical priming, local anesthetics and non-pharmacological interventions (e.g. pre-insertion counselling and the effect of an assistant providing reassurance and distraction during the procedure). ${ }^{19}$ As these regimes are adapted from other surgical procedures, they are actually not IUD insertionspecific and there is no clear data about at which step of IUD application they block pain. The highest pain level was observed during the IUD application while the lowest one was during the tenaculum application in this study.

In the light of the studies stating that use of NSAIDs and misoprostol is not superior to placebo, routine prophylactic use of these agents in IUD application is not recommended. ${ }^{20}$ It was observed that tramadol and naproxenin mitigated pain in some specific groups. ${ }^{21}$ It was shown that use of topical lidocaine $2 \%$ gel did not have any effect on the pain scores after tenaculum placement, application and procedure in IUD insertion. $^{22,23}$ Nevertheless, there are studies being published which show that topical use of different formulations involving high concentrations of lidocaine mitigates IUD insertion pain at every step of the procedure. ${ }^{24-26}$ It was shown that paracervical blockage in injectable applications of local anesthetics mitigates IUD application pain but intracervical injectival application is not effective on the pain. ${ }^{3,27}$ In consideration of injection's own pain and possible adverse reactions, topical application of local anesthetics is regarded as being more advisable.

Levobupivacaine used in this study was preferred due to having less cardiotoxicity and central nervous system toxicity and longer-term effective agent than lidocaine. ${ }^{28}$ To the best of our knowledge, present study is the first study reported in the literature investigating the levobupivacaine with intrauterine anesthesia before the IUD application.

Duration of local anesthetic to be effective is significant as well. The culmination effect of anesthetic subsequently topical application of $1 \%$ lidocaine develops in $10 \mathrm{~min}$ $(20 \mathrm{nK})$. In this study, prior to removing the catheter due to the need for a longer period to attain an anesthetic effect for levobupivacaine, 15 minutes have been waited after instillation of local anesthetic agents. The volume of $5 \mathrm{~mL}$ of anesthetic utilized in our trials is sufficient to fill the uterine cavity. At this volume, tubal extravasation of the drug was also prevented.

Since pain is a sensitive indication and hard to classify, anxiety is likely to have arisen as an confounding factor. Moreover, ethnic and cultural diversities of patients likely to have influence on pain attitude and tolerance. Evaluation of expecting pain might be of value in order to determine the real pain. The amount of speculum insertion is possibly an alternate for a patient's total tolerance of pain and/or anxiety. Some of the many conditions such as dyspareunia, vulvar vestibular syndrome and vaginismus lead to occur pain with speculum. Therefore, the subjects who experienced pain with speculum during insertion as a result of anxiety distribution were excluded in order to control for potential confounding factor.

The most important limitations of the study are that there was no lidocaine group, shorter period of post-procedure evaluation and insufficient size of sample. Our data analysis proved a statistically significant decrease in pain during IUD insertion with intrauterine levobupivacaine in reproductive age women. Even though instillation is likely to extend the procedure time, the relief from pain for the patient is worthy and overcome the time factor. On the other hand, it may be not the case because we did not assess satisfaction with the entire procedure. Amid local anesthetic variables, lidocaine may have an advantage over levobupivacaine because of the shorter time needed for initiation of its effect. We used the same 15 min interval between instillation and the procedure to be able to effect of levobupivacain group. These items may be accepted as major limitations of the present study. The length of interval may be perceived as too long and accepted as a drawback of the study.

\section{CONCLUSION}

Despite the fact that IUD insertion is a painful process the usage of intracavitary levobupivacain could be named as an effective methods of pain control at IUD insertion and during the post interval period. Nevertheless, additional researches on bigger groups are necessary to detect optimal concentration, volume and waiting time in accordance with the trait of local anesthetic agent and applicability of the method to other intrauterine procedures.

\section{Funding: No funding sources Conflict of interest: None declared \\ Ethical approval: The study was approved by the Institutional Ethics Committee}

\section{REFERENCES}

1. Peipert JF, Zhao Q, Allsworth JE. Continuation and satisfaction of reversible contraception. Obstet Gynecol. 2012;117:1105-13.

2. Goldstuck ND. Pain reduction during and after insertion of an intrauterine contraceptive device. Adv Contracept. 1987;3:25-36.

3. Cirık DA, Taşkın EA, Tuğlu A, Ortaç A S, Dai Ö. Paracervical block with $1 \%$ lidocaine for pain control during intrauterine device insertion: A prospective, single-blinded, controlled study. Int J Reprod Contracept Obstet Gynecol. 2013;2:263-7.

4. Rubin SE, Winrob I. Urban female family medicine patients' perceptions about intrauterine contraception. J Women Health (Larchmt). 2010;19:735-40.

5. Maguire K, Davis A, Rosario Tejeda L. Intracervical lidocaine gel for intrauterine device insertion: a 
randomized controlled trial. Contraception 2012;86:214-9.

6. Chor J, Bregand-White J, Golobof A, Harwood B, Cowett A. Ibuprofen prophylaxis for levonorgestrelreleasing intrauterine system insertion: a randomized controlled trial. Contraception. 2011;85:558-62.

7. Dijkhuizen K, Dekkers OM, Holleboom CA, Groot de CJ, Hellebrekers BW, van Roosmalen GJ, et al. Vaginal misoprostol prior to insertion of an intrauterine device: an RCT. Hum Reprod. 2011;26:323-9.

8. Oloto E, Bromham D, Murty J. Pain and discomfort perception at IUD insertion-effect of short-duration, low-volume, intracervical application of two percent lignocain gel (Instillagel)-a preliminary study. Br J Fam Plann. 1996;22:177-80.

9. Mody SK, Kiley J, Rademaker A, Gawron L, Stika C, Hammond C. Pain control for intrauterine device insertion: a randomized trial of $1 \%$ lidocaine paracervical block. Contraception. 2012;86(6):704-9.

10. Costello MF, Horrowitz S, Steigrad S, Saif N, Bennett M, Ekangaki A. Transcervical intrauterine topical local anesthetic at hysterosalpingography: a prospective, randomized, double-blind, placebocontrolled trial. Fertility sterility. 2002;78(5):111622.

11. Tornblom-Paulander S, Tingaker BK, Werner A, Liliecreutz C, Conner P, Wessel H, EkmanOrdeberg, G. Novel topical formulation of lidocaine provides significant pain relief for intrauterine device insertion: pharmacokinetic evaluation and randomized placebo-controlled trial. Fertility sterility. 2015;103(2):422-7.

12. Bijur PE, Silver W, Gallagher EJ. Reliability of the visual analog scale for measurement of acute pain. Acad emer med. 2001;8(12):1153-7.

13. Maguire K, Morrell K, Westhoff C, Davis A. Accuracy of providers' assessment of pain during intrauterine device insertion. Contraception. 2014;89(1):22-4.

14. Nelsona AL, Fong JK. Intrauterine infusion of lidocaine does not reduce pain scores during IUD insertion. Contraception. 2013;88:37-40.

15. Trolice MP, Fishburne C Jr, McGrady S. Anesthetic efficacy of intrauterine lidocaine for endometrial biopsy: a randomized double-masked trial. Obstet Gynecol. 2000; 95:3, 345-7.

16. Dogan E, Celiloglu M, Sarihan E, Demir A. Anesthetic effect of intrauterine lidocaine plus naproxen sodium in endometrial biopsy. Obstet Gynecol. 2004;103:347-51.

17. Hubacher D, Reyes V, Lillo S, Zepeda A, Chen PL, Croxatto H. Painfrom copper intrauterine device insertion: randomized trial of prophylactic ibuprofen. Am J Obstet Gynecol. 2006;195:1272-7.
18. Sanford M, Keating GM. Levobupivacaine. Drugs. 2010;70(6)761-91.

19. Danielsson GK, Mansour D, Fiala C, Kaunitz AM, Bahamondes L. Management of pain associated with the insertion of intrauterine contraceptives. Hum Reprod Update. 2013, dmt022. May 12 [epub ahead of print].

20. Lopez LM, Bernholc A, Zeng Y, Allen R H, Bartz D, O'Brien PA, Hubacher D. Interventions for pain with intrauterine device insertion. The Cochrane Library. Cochrane Database of Systematic Reviews. 2015;7: CD007373

21. Karabayirli S, Ayrım AA, Muslu B. Comparison of the analgesic effects of oral tramadol and naproxen sodium on pain relief during IUD insertion. J Minimally invasive gynecol. 2012;19(5)581-4.

22. Maguire K, Davis A, Tejeda LR, Westhoff C. Intracervical lidocaine gel for intrauterine device insertion: a randomized controlled trial. Contraception. 2012;86(3,) 214-9.

23. McNicholas CP, Madden T, Zhao Q, Secura G, Allsworth JE, Peipert JF. Cervical lidocaine for IUD insertional pain: a randomized controlled trial. Am J Obstet Gynecol. 2012;207(5):384-e1.

24. Paulander TS, Tingaker BK, Werner A, Liliecreutz C, Conner P, Wessel H, Ordeberg EG. Novel topical formulation of lidocaine provides significant pain relief for intrauterine device insertion: pharmacokinetic evaluation and randomized placebocontrolled trial. Fertility Sterility. 2015;103(2)422-7.

25. Aksoy H, Aksoy U, Ozyurt S, Acmaz G, Babayigit M. Lidocaine $10 \%$ spray to the cervix reduces pain during intrauterine device insertion: a double-blind randomised controlled trial. J Fam Planning Reprod Health Care. 2016;42(2):83-7.

26. Tavakolian S, Doulabi MA, Baghban AA, Mortazavi A, Ghorbani M. Lidocaine-prilocaine cream as analgesia for IUD insertion: a prospective, randomized, controlled, triple blinded study. Global J Health Sci. 2015;7(4)399.

27. Allen RH, Bartz D, Grimes DA, Hubacher D, O'Brien P. Interventions for pain with intrauterine device insertion. The Cochrane Library. 2009;8(3):CD007373

28. Burlacu CL, Buggy DJ. Update on local anesthetics: focus on levobupivacaine. Therapeutics Clin Risk Management. 2008;4(2)381.

Cite this article as: Akgun N, Keskin E, Kalem MN, Bakirarar B. Intrauterine levobupivacaine for pain control during intrauterine device insertion. Int $\mathbf{J}$ Reprod Contracept Obstet Gynecol 2017;6:1117-21. 